\title{
Estratégias criativo-inovadoras de comunicação institucional de empresas em mídias sociais digitais: casos Itaú, 0 Boticário e Cacau Show
}

Creative-innovative strategies of corporate communication of companies in digital social media: the Itaú, 0 Boticário and Cacau Show cases

Estrategias creativo-inovadoras de comunicación institucional de empresas en medios digitales: casos Itaú, 0 Boticário y Cacau Show

Felipe Chibás Ortiz

- Doutor em Ciências da Comunicação pela Escola de Comunicações e Artes da Universidade de São Paulo (ECA-USP)

- Mestre em Integração Latino-americana pela Universidade de São Paulo (Prolam-USP)

- Especialista em Marketing Direto pela Universidade Alcalá de Henares, Espanha

- Ex-diretor da empresa Perfectu, representante da Global Estrategia, multinacional

- franco-espanhola de marketing digital e ensino a distância

- Professor na ECA-USP

- Autor do livro M@rketing pessoal.com: sua estratégia, dentro e fora da internet

- Organizou o livro Gestão da educação a distância: comunicação, desafios e estratégias e co-organizou Marketing e comunicação: experiências brasileiras e cubanas

- E-mail:chibas_f@yahoo.es

\section{Melanie Cipolla}

- Especialista em Gestão Estratégica em Comunicação Organizacional e Relações Públicas pela Escola de Comunicação de Artes da Universidade de São Paulo (ECA-USP)

- Especialista em Comunicação Corporativa pela Escola Superior de Propaganda e Marketing (ESPM/SP)

- Graduada em Comunicação Social - Publicidade e Propaganda pela Faculdade Cásper Líbero (Facásper)

- Tem experiência em planejamento estratégico e marketing promocional em garndes empresas

- Co-oorganizadora do Startup Weekend Google São Paulo

- Mentora do Design Thinking Weekend - WTC/SP

- E-mail: mkt.melcipolla@gmail.com 


\section{Resumo}

Este artigo aborda de maneira preliminar as estratégias criativas e inovadoras de comunicação institucional das empresas Itaú, 0 Boticário e Cacau Show, ao analisar a utilização das redes sociais digitais por parte delas. A metodologia empregada foi o estudo multicaso, com análise qualiquantitativa dos dados. Apresenta-se um sistema de variáveis e indicadores para mensurar e identificar quais são as estratégias de comunicação institucional de caráter criativo e inovador que utilizam algumas das empresas mais inovadoras do Brasil nas mídias sociais digitais, de acordo com o ranking consultado. Os resultados obtidos apontam que a estratégia de fazer um investimento privilegiado na comunicação institucional, deixando em segundo plano o da mercadológica, além de ser considerada uma estratégia criativa condizente com o comportamento padrão do mercado na atualidade, pode vir a oferecer bons dividendos.

\section{PALAVRAS CHAVE: REDES SOCIAIS • INOVAÇÃO • CRIATIVIDADE • COMUNICAÇÃO INTEGRADA • GESTÃO DA COMUNICAÇÃO}

\section{Abstract}

This article addresses in a preliminary way the creative and innovative strategies of institutional communication of the Itaú, 0 Boticário and Cacau Show enterprises, when analyzing the use by them of the digital social networks. The methodology used was a multi-case study with and qualitative and quantitative analysis of the data. A system of variables and indicators is presented to measure and identify which are the institutional communication strategies of a creative and innovative nature used by some of the more innovative Brazilian companies in the digital social media, pursuant to the ranking consulted. The results obtained point to strategy making a privileged in institutional communication, leaving the merchandising at a second level, in addition to be considered as a creative strategy that is appropriate for the current market standard, which can offer good dividends.

\section{KEYWORDS: SOCIAL NETWORK•INNOVATION •CREATIVITY •INTEGRATED COMMUNICATION•COMMUNICATION MANAGEMENT.}

\section{Resumen}

Este artículo aborda de manera preliminar las estrategias creativas e innovadoras de comunicación institucional de las empresas Itaú, 0 Boticário y Cacau Show, al analizar la utilización de las redes sociales digitales por parte de las mismas. La metodología empleada fue el estudio multicaso, con análisis cuali-cuantitativo de los datos. Se presenta un sistema de variables e indicadores para mensurar e identificar cuáles son las estrategias de comunicación institucional de carácter creativo e innovador que utilizan algunas de las empresas más innovadoras del Brasil y los medios sociales digitales, de acuerdo con el ranking consultado. Los resultados obtenidos apuntan que la estrategia de hacer una inversión privilegiando la comunicación institucional, dejando en segundo plano el de la mercadológica, además de ser considerada una estrategia creativa acorde con el comportamiento padrón del mercado en la actualidad, puede venir a ofrecer buenos dividendos. 
0

estudo do comportamento das organizações e pessoas nas redes e mídias sociais é um excelente caminho metodológico para entender os paradigmas de comunicação do ser humano na atualidade (Di Felice, 2012), ainda mais num país como o Brasil, onde os internautas podem ficar até mais de quatro horas na web, em média (Chagas, 2014). As mídias sociais digitais são uma magnífica ferramenta para as empresas na busca de atingir seus objetivos (Gabriel, 2010; Turchi, 2012), como é de amplo conhecimento. Isto se torna cada vez mais onipresente, conforme atestam os dados de internet que resultam surpreendentes, como os de que o Brasil é o país no qual os internautas passam mais tempo na web (Caputo, 2014). Na atualidade, as redes sociais digitais não são utilizadas apenas como instrumentos de comunicação mercadológica e estratégia comercial, mas também como instrumentos da comunicação institucional, redundando em estratégias de relacionamento e fidelização do cliente.

Tal aspecto decorre de diversos fatores, dentre os quais destacamos o fato de que os novos públicos e atores tecnossociais apresentam novos comportamentos como consumidores e cobram da sociedade e das empresas novas formas de abordagem e relacionamento, interessando-se constantemente pela reputação da organização e não apenas pela qualidade de seus produtos e serviços (Rosa, 2006; Terra, 2011).

Este artigo pretende responder à questão referente às estratégias digitais de comunicação institucional de caráter inovador utilizadas por algumas empresas do Brasil. Ainda, se é possível elaborar claros indicadores de criatividade - de preferência quantificáveis - que permitam visualizar, de forma clara, se a estratégia de comunicação institucional utilizada pela empresa nas mídias sociais foi ou não criativa.

Para tanto se fez uso da metodologia de estudo multicaso (Yin, 2009), que permitiu comparar na base de indicadores anteriormente predefinidos pelos autores a comunicação institucional de ordem criativa nos casos das empresas Itaú, 0 Boticário e Cacau Show, escolhidas por se encontrarem entre as cinquenta empresas mais inovadoras de 2014, segundo o ranking da revista Exame (2014). 0 intuito foi conferir se essas três empresas, posicionadas entre as mais inovadoras do Brasil quanto à sua estratégia geral e comercial, de acordo com os produtos e serviços oferecidos, tinham também uma estratégia de comunicação institucional digital criativa e inovadora.

\section{DIALOGANDO SOBRE CRIATIVIDADE, INOVAÇÃO E ESTRATÉGIAS DE COMUNICAÇÃO}

A criatividade tem sido definida pelos mais diversos autores com ênfase, quase sempre, voltada para a ótica da perspectiva psicológica. Para os efeitos deste estudo, entretanto, optou-se por enunciá-la de forma a extrapolar esses limites e integrar outros elementos. Assim, resulta útil a definição de criatividade quântica proposta por Saturnino de la Torre (2008, p. 38): "Entende-se também como uma energia pulsante que integra os esforços em extensas redes homem-natureza-máquina com a finalidade de criar ideias, produtos e serviços novos". Essa criatividade coletiva, proposta pelo autor, está sendo construída mediante diversos ecossistemas de comunicação, mas especialmente por meio do ciberespaço, tendo como uma das suas consequências o surgimento e a consolidação da cibercultura.

Desta forma, é possível afirmar que existe na atualidade uma criatividade digital que é aplicada ao mundo virtual e que utiliza os veículos digitais. Refere-se à utilização, de forma criativa, dos recursos da comunicação digital que oferecem as 
chamadas novas tecnologias da informação e comunicação (NTCls) para gerar resultados inovadores e que respondam às necessidades dos usuários e públicos envolvidos no processo, com a finalidade de criar ideias, produtos e serviços novos.

Estas contribuições criativas serão ainda maiores no futuro, uma vez que o número das comunidades virtuais, seus projetos, interações e alcance vêm sendo largamente incrementadas, surgindo com isso novas e inesperadas demandas sociais e profissionais. Nesse sentido, segundo Alexandra Okada (2011), são conceitos complementares aqueles de coaprendizado, coparticipação, cocriação e copropriedade, que aludem à criação conjunta de conteúdos na internet.

0 conhecimento e a informação são compartilhados de maneira mais rápida e simples mediante 0 acesso a essas novas tecnologias, que permitem aprender e criar de forma participativa em plataformas abertas de criação coletiva, proporcionadas pelas redes sociais ou pela própria empresa posicionada na internet, onde também a propriedade daquilo que foi criado conjuntamente é dividida.

Novas competências comunicativas (Donnelly; Boniface, 2013), assim como estratégias e formas de abordagem referentes aos clientes e aos diversos públicos de interesse são necessárias e deverão ser devidamente diagnosticadas e desenvolvidas. Tudo isso vem ao encontro das ideias de Henry Jenkins (2009) sobre a cultura participativa e a mudança do olhar do consumidor, que deseja dividir experiências e informações com amigos e colegas - e não apenas desfrutar individualmente de um produto ou serviço. Esse novo consumidor-emissor deseja participar da criação e das decisões relativas aos mesmos.

Entre os indicadores de criatividade mais citados, e que também podem ser utilizados para avaliar as estratégias com resultados inovadores das empresas nas mídias sociais, encontram-se a originalidade, a flexibilidade, a solução de problemas e a aceitação de desafios (Chibás Ortiz, 2015).

\section{A COMUNICAÇÃO ORGANIZACIONAL ESTRATÉGICA}

De acordo com Margarida Kunsch (2003, p. 150), a gestão da comunicação é um conceito amplo de caráter estratégico, definindo-se a comunicação integrada como "uma filosofia que direciona a convergência das diversas áreas, permitindo uma atuação sinérgica. Pressupõe uma união ou imbricação radicular da comunicação institucional, comunicação mercadológica, comunicação interna e comunicação administrativa".

Esse conceito tem especial importância para a compreensão das estratégias de comunicação de uma empresa, pois a prioridade dedicada a algumas das modalidades da comunicação acima descritas é muito variável, tendo isso grande peso no planejamento e na implementação das suas estratégias de comunicação. Persiste ainda hoje, em muitas organizações, a tendência de priorizar a comunicação mercadológica. Neste ponto, é necessário afirmar que a estratégia possui vários níveis, como destacado por outros autores (Corrêa, 2003). Por isso, além de se ter uma estratégia geral integrando os veículos de comunicação física tradicionais (televisão, rádio, imprensa impressa etc.) e os da web (site, blog, links patrocinados, disparo de e-mails, diretórios etc.), se sugere ter uma estratégia específica para as mídias sociais (Facebook, Twitter, Youtube, Linkedin etc.), dada a diversidade e especificidade de cada uma delas. 
Tal aspecto pressupõe a existência de um conceito de gestão de redes virtuais. Trata-se de administrar os recursos e contatos no ciberespaço com vistas a atingir um objetivo: mailings, horários, número de contatos diários, semanais ou mensais, dentre outros. Significa também integrar a comunicação nas diversas mídias e veículos digitais, como site, blog, links patrocinados, mídias sociais, disparo de e-mails, SMS, assim como nos veículos físicos, fôlderes, outdoors e outros canais mais conhecidos ou tradicionais, como anúncios na tevê, rádio, imprensa etc.Trata-se de ter uma estratégia digital que transcenda a utilização isolada ou esporádica de um meio ou canal de comunicação com o cliente, o que implica 0 fato de haver planejamento (planos de mídia), objetivos e metas claras, pesquisa (relatórios, gráficos), indicadores de avaliação e mensuração (índices de satisfação do cliente, reputação, vendas, boca a boca virtual etc.). A ideia da necessária interconexão resulta essencial para entender que a comunicação decorre de processos complexos de interações e relações de interdependência (Chibás Ortiz, 2013).

Dentro das quatro modalidades de comunicação Integrada, Kunsch (2003) destaca a comunicação institucional, e dentro dela, os instrumentos que são: relações públicas, jornalismo empresarial, assessoria de imprensa, editoração multimídia, imagem corporativa, identidade corporativa, propaganda institucional, marketing social e marketing cultural. Para 0 presente estudo, o foco será posto nas estratégias criativas de propaganda institucional utilizando as mídias sociais digitais.

\section{ESTRATÉGIAS DE COMUNICAÇÃO INOVADORAS}

A criatividade e a inovação são itens diferentes, mesmo que relacionados; a primeira se refere mais à ideia, à elaboração e ao planejamento de um processo ou serviço; a segunda diz respeito à obtenção de um resultado com a implementação do antes planejado (Chibás Ortiz; Pantaleón; Rocha, 2013).

A criatividade na comunicação institucional pode ser entendida como criar ou valer-se de metodologias de comunicação diferenciadas, ao utilizar os veículos de forma inusitada, propor novas formas de enxergar um produto ou serviço e estruturar as campanhas de uma forma nova. Já a inovação em comunicação institucional poderia ser vista como capacidade de obter os resultados esperados a partir da implementação desse planejamento criativo.

Por estratégia de comunicação criativa e inovadora entendem-se, nos limites deste texto, aquelas estratégias de comunicação que se adequam aos parâmetros definidos pelas pesquisas Fast Company (Fast Company, 2014) e Prêmio Best Innovation (Época, 2014). Segundo a Fast Company (2014), os critérios que ajudam a classificar as estratégias de inovação das empresas são: 1. Velocidade da evolução; 2. Aprimoramento constante; 3 . Ambição das propostas - aquelas cujas inovações exercem impacto na indústria e na cultura.

Esses critérios podem ser complementados com os cinco parâmetros para avaliar o grau de inovação das empresas que foram elencados pela pesquisa realizada para outorgar o prêmio Best Innovator (2014), aqui também empregados. São eles: 1. Estratégia: avalia se a estratégia de inovação é desenvolvida e implementada pela alta gestão e se está vinculada à da companhia; verifica se há metas quantitativas e qualitativas a alcançar; 2. Processos: como a empresa se estrutura para gerar ideias e implementá-las; verifica se há métricas para tornar o processo eficiente e se são consultadas fontes 
externas; 3. Organização e cultura: examina se a cultura de inovação está disseminada na organização, como se desenvolve e como está estruturada; 4. Resultado da inovação: se é única e original, se tem potencial para promover outras e qual seu impacto no lucro da empresa; são analisadas a qualidade e a evolução das métricas de inovação.

\section{METODOLOGIA}

0 método de pesquisa utilizado foi o qualiquantitativo e o teórico-prático, com ênfase no estudo multicaso (Yin, 2009). As técnicas de pesquisa que se desdobraram nesses métodos gerais foram o levantamento bibliográfico e a revisão de documentos físicos e na web (sites, blogse redes sociais) das empresas em questão no período de janeiro até 10 de março de 2015. Também foi utilizada a análise de conteúdo das postagens utilizadas pelas empresas nas mídias sociais selecionadas no período de 14 de janeiro a 15 de março de 2015 (sessenta dias).

\section{Amostragem}

Selecionamos três empresas de grande porte e representatividade no país: o Banco Itaú, a empresa de cosméticos 0 Boticário e a de chocolates Cacau Show. 0 principal critério de seleção foi o fato de as três estarem presentes no ranking de inovação de 2014 da revista Exame (2014). Para seguir o comportamento das empresas escolhidas, foram selecionadas as cinco mídias sociais mais importantes para o mercado brasileiro (Olhar Digital, 2014) e para as marcas em questão, a saber: Linkedin, Facebook, Twitter, Instagram e Youtube. Optou-se pela frequência simples e aplicação do teste de Tucker nos casos em que foi preciso determinar se as diferenças eram significativas.

\section{Procedimentos}

Unindo os critérios acima citados, definidos pelas pesquisas Fast Company (2014) e Prêmio Best Innovation (Época, 2014), com os mais tradicionais de pesquisa da criatividade já utilizados antes por diversos autores, tais como os de originalidade, solução criativa de problemas, aceitação de desafios e flexibilidade (Chibás Ortiz, 2014), elaboraram-se os parâmetros e indicadores de criatividade para avaliar as estratégias de comunicação institucional utilizadas pelas empresas nas mídias sociais digitais, a seguir descritos:

1. Originalidade: elaboração e implementação de uma estratégia de comunicação diferenciada original.

1.1 Quantidade de postagens que fazem analogia com conceitos do dia a dia

1.2 Quantidade de histórias reais correlacionadas com o conceito da campanha

1.3 Quantidade de ilustrações customizadas para o público-alvo

1.4 Propaganda institucional

1.5 Quantidade de postagens institucionais

1.6 Quantidade de postagens mercadológicas

2. Flexibilidade: saber ouvir seu público na web, mudando de estratégia e tática empresarial de comunicação, caso seja necessário. 
2.1 Quantidade de canais de comunicação que disponibiliza para o público em cada mídia social

2.2 Quantidade de postagens que incentivam o usuário a dar feedback para a marca

3. Solução criativa de problemas: a estratégia de comunicação adotada caracteriza-se por estimular a criação conjunta com o público-alvo de soluções para os problemas e desafios referentes à implementação dos produtos e serviços oferecidos pela empresa.

3.1 Quantidade de postagens que estimulam a cocriação de soluções, peças, testemunho e interação de pessoas

3.2 Quantidade de postagens que estimulam a coparticipação, ou a tomada de decisões conjuntas do público com a empresa

4. Aceitação de desafios: assumir desafios durante a campanha, estipular metas complexas no que diz respeito aos resultados esperados, a parcerias, número de usuários, engajamento, dentre outros aspectos.

4.1 Quantidade de empresas parceiras participando da campanha nas mídias sociais

4.2 Quantidade de games elaborados e utilizados na campanha

4.3 Quantidade de outros aplicativos criados e utilizados na campanha

4.4 Quantidade de concursos culturais criados para a campanha

4.5 Quantidade de redes sociais nas quais a empresa está presente

5. Engajamento: resultado obtido em termos de compromisso do cliente ou prospect com a empresa, desde seguir as postagens da organização, gostar da proposta da mesma e o nível de envolvimento, interação, intimidade e influência que um indivíduo tem com uma marca

5.1 Quantidade de curtidas e compartilhamentos das postagens institucionais

5.2 Quantidade de curtidas e compartilhamentos das postagens mercadológicas

5.3 Quantidade de participantes e seguidores

5.4 Quantidade de postagens que estimulam a criação de comunidades favoráveis à marca com o público-alvo

5.5 Quantidade de postagens que estimulam a responsabilidade social

Esses parâmetros foram utilizados na análise de conteúdo das postagens das empresas nas mídias sociais selecionadas.

\section{ANÁLISE E DISCUSSÃO DE RESULTADOS}

A seguir serão descritos os principais resultados obtidos para cada empresa nas mídias sociais estudadas. Optou-se por trabalhar com a frequência simples e aplicação do teste de Tucker nos casos em que foi necessário determinar se as diferenças eram significativas.

O Quadro 1 mostra os principais resultados obtidos sobre a utilização das mídias sociais digitais pelo Banco Itaú. 
Quadro 1 - Mídias utilizadas pelo Banco Itaú: parâmetros e indicadores de criatividade

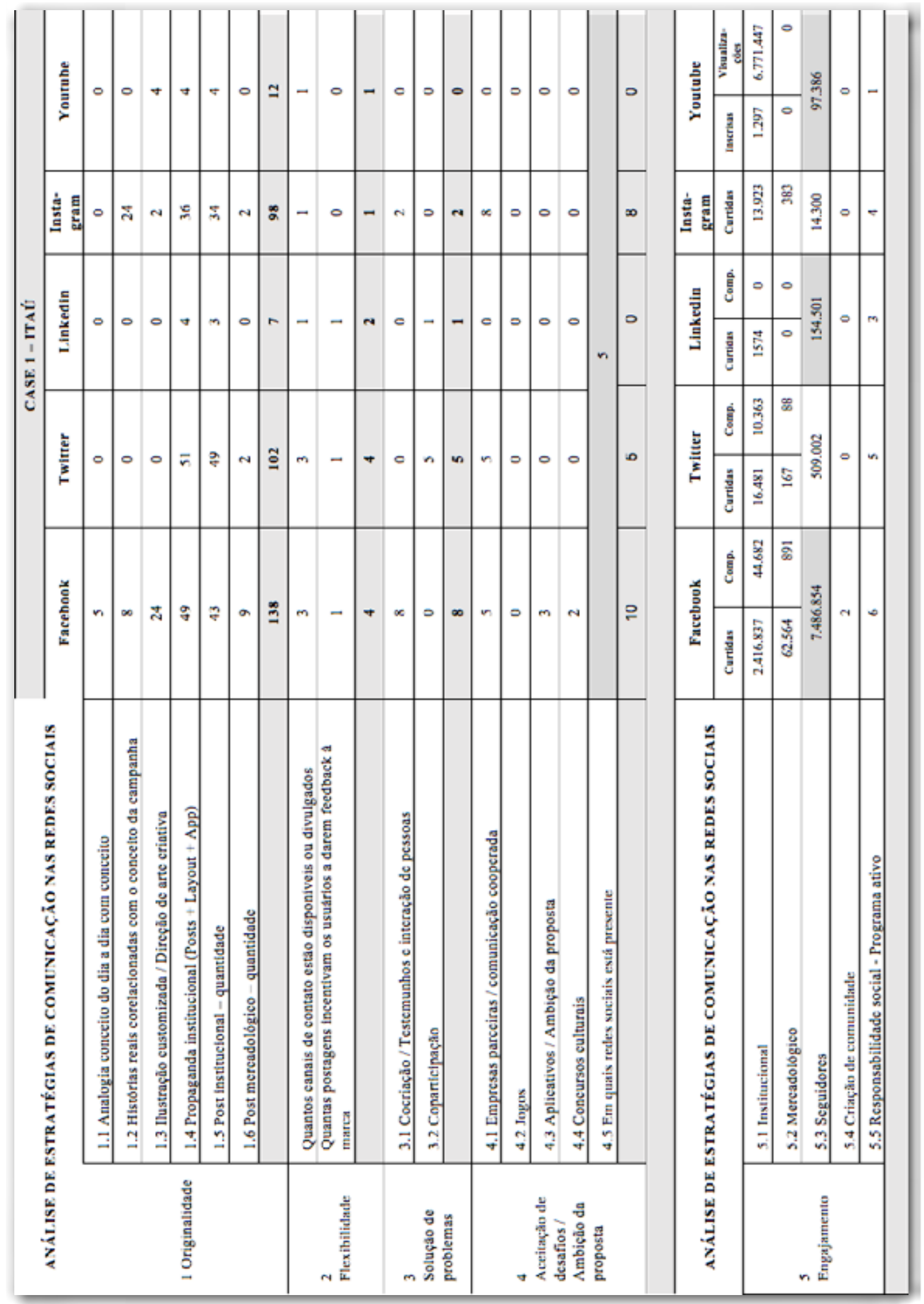

Fonte: Arquivo dos autores.

Na variável originalidade, o Itaú faz muito mais postagens de propaganda institucional (43 no Facebook e 49 no Twitter, por exemplo) do que mercadológica (nove no Facebook e duas no Twitter), o que pode ser classificado, se comparado com outras empresas que buscam dar sempre maior ênfase nas postagens mercadológicas, como uma estratégia diferenciada, original.

No quesito originalidade, é possível incluir também o fato de que o Itaú trabalha utilizando histórias reais que o banco ajudou a realizar direta ou indiretamente, o que transfere uma forte reputação ao usuário, que sente a atenção e importância que a organização tem pelos seus sonhos. No período analisado foram feitas oito postagens referentes a histórias de vida no Facebook e 24 no Instagram. 


\section{ANO 12 • NÚMERO $22 \cdot 1^{0}$ sem. 2015 - ORGANICOM \\ ESTRATÉGIAS CRIATIVO-INOVADORAS DE COMUNICAÇÃO INSTITUCIONAL DE EMPRESAS EM MÍDIAS SOCIAIS DIGITAIS: CASOS ITAÚ, O BOTICÁRIO E CACAU SHOW}

Na variável solução de problemas, destaca-se o indicador cocriação, no qual o Itaú fez oito postagens no Twitter e duas no Instagram, estimulando os usuários a contribuir, participar e interagir ativamente para a formação de conteúdo.

Na variável aceitação de desafios, tem destaque a ação em cooperação com empresas parceiras, na qual o Itaú investe, sendo um total de cinco ações desse tipo no Facebook e Twitter. Com isso, agrega valor estratégico para a comunicação institucional, pois reforça a imagem da empresa, trazendo ao mesmo tempo o melhor de outros serviços e produtos também desejados para seus correntistas ou prospects. 0 conteúdo pode ser percebido pelo público-alvo como interessante e relevante e entendido como uma postura parceira.

Na análise do Itaú, é preciso que se ressalte que a soma de postagens curtidas nas cinco redes sociais observadas atingiu o total de 2.450 .112 no período analisado (60 dias), do que se pode inferir que em torno de 2 milhões de pessoas admiraram, interagiram e fizeram questão de registrar o que lhes agradou, a ponto de gerar uma ação (curtir).

Para avaliar a variável engajamento, medimos o número de compartilhamentos nas três redes sociais que possuem essa ferramenta de comunicação (o comando compartilhar). 0 Itaú atingiu 55.045 compartilhamentos de posts institucionais versus 1.146 compartilhamentos de posts mercadológicos, ou seja, o público sentiu uma grande vontade de mostrar o que achou de interessante nas postagens do Itaú para os outros. Isso indica que não apenas admirou, mas fez questão de dividir e distribuir a propaganda institucional elaborada pelo Itaú para seus contatos e círculo social na rede. Esse aspecto reflete o forte engajamento gerado pelas campanhas desenvolvidas pelo Itaú. Esse indicador também pode ser analisado atrelado à competência de conteúdo interessante para o público-alvo, o que remete ao nosso critério de originalidade.

0 item 4.3 avalia se as marcas usam o recurso de aplicativos para interação com os usuários. 0 Itaú atualmente disponibiliza três aplicativos no Facebook: A.i Itaú Uniclass, a Árvore dos sonhos e a Poltrona Itaú sob um novo ponto de vista. No item 4.4 Concurso cultural, o Itaú está presente com duas ações: Deixe a música mudar o seu mundo e Folião da vez.

0 item 5.5 avalia também o compromisso, através de postagens referentes a programas sociais divulgados. 0 Itaú ofereceu seis ideias de caráter social, a saber: a) Incentivo ao teatro, 50\%; b) Incentivo ao cinema, 50\%; c) Incentivo ao uso de bikes; d) Educação Financeira para crianças; e) Itaú Viver mais com a terceira idade; e f) Troca de livros nas bikes. No Twitter foram cinco posts, no Linkedin, três; no Instagram, quatro; e um no Youtube.

Ao se delinear um resumo da perspectiva da criatividade da estratégia de comunicação institucional nas mídias sociais digitais do Itaú, é possível afirmar que este apresentou alta originalidade, solução de problemas e flexibilidade e aceitação de desafios médias. Tal perspectiva pode ser percebida no Gráfico 1.

Gráfico 1 - Estratégia criativo-inovadora do Itaú nas mídias sociais.

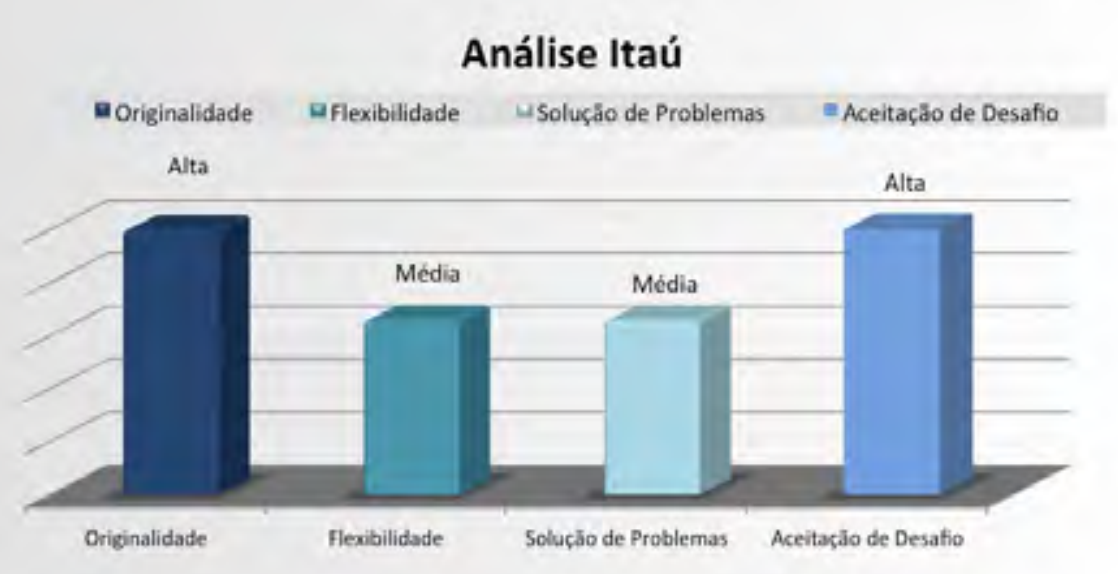

Fonte: Arquivo dos autores. 
De maneira geral, pelos números coletados no período pesquisado, pode-se perceber uma ênfase maior na estratégia do Itaú na utilização das redes sociais Facebook e Twitter do que nas demais mídias observadas.

A seguir, o Quadro 2 mostra os principais resultados obtidos pela empresa 0 Boticário no tópico referente às estratégias de comunicação institucional criativa utilizando as mídias sociais digitais.

Quadro 2 - Mídias utilizadas por 0 Boticário: parâmetros e indicadores de criatividade

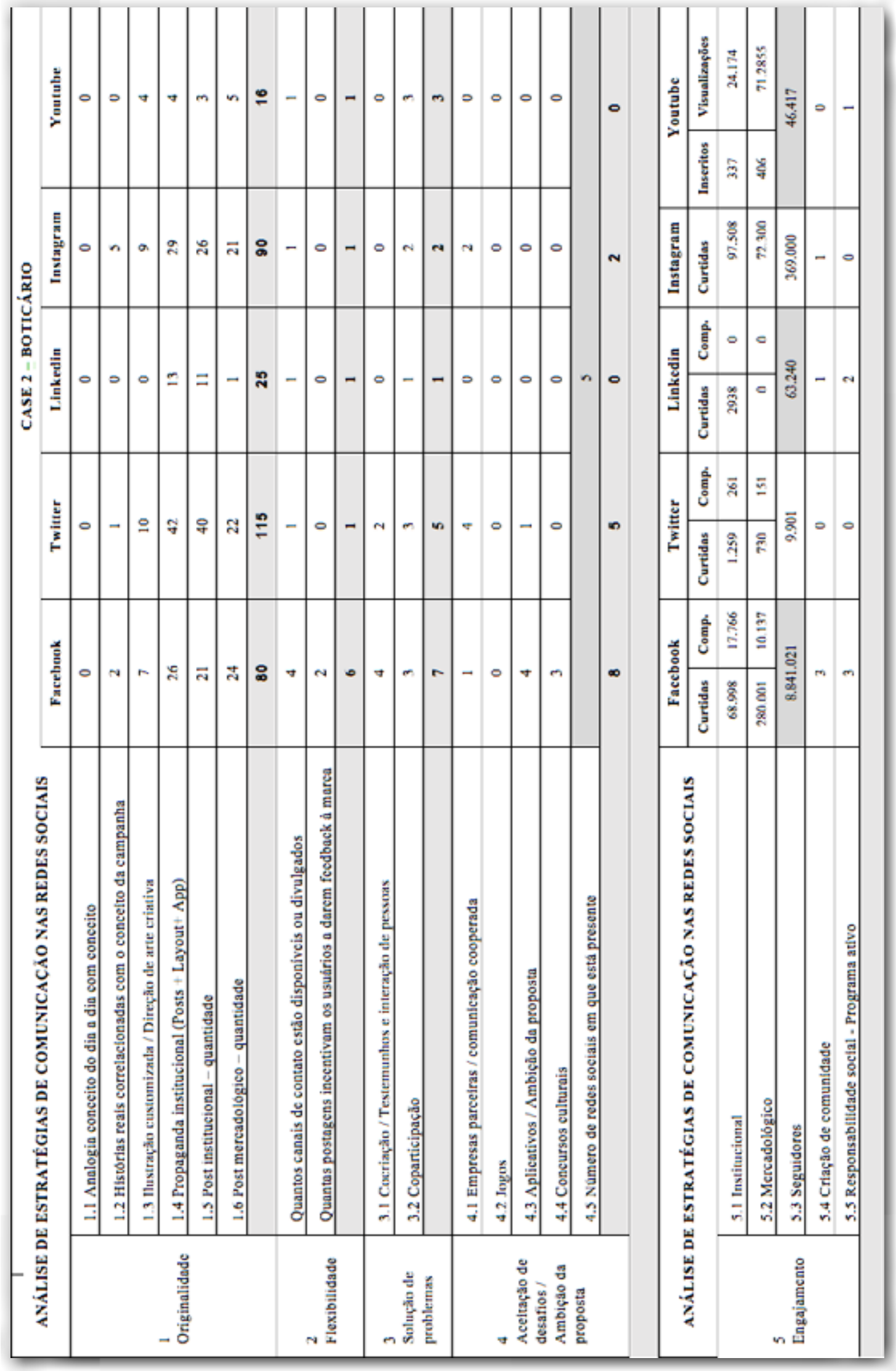

Fonte: Arquivo dos autores. 
$(53,3 \%)$, quase $50 \%$ de cada estratégia de comunicação. Assim, 0 Boticário, no caso das redes sociais analisadas nesse período, teve uma estratégia, bastante equilibrada, o que também pode ser visto como uma estratégia criativa, dado que não seguiu a tradicional forma de investir - de uma maneira muito mais aberta - na comunicação mercadológica.

A variável flexibilidade, na análise de 0 Boticário, se destacou por conter o maior número de canais de comunicação/contato direto em uma única rede social, somando quatro espaços/oportunidades para os consumidores ou usuários darem seu feedback, perguntarem, criticarem ou só comentarem. E mesmo, 0 Boticário é o único a ter um aplicativo na interface do Facebook chamado "Fale com 0 Boticário", que ratifica sua preocupação e real proatividade em querer saber o feedback dos públicos com os quais se relaciona. Isto nos mostra uma alta flexibilidade, entendida como escutar o cliente sem impor sua opinião para mudar se for preciso, melhorar sempre e entregar algo além dos produtos.

0 Boticário pontua, no total de curtidas, 171.040, e no de compartilhamentos, 18.027, na soma das cinco redes sociais analisadas, muito menos que todas as empresas analisadas. Do que se depreende que a marca atrai as pessoas para seguila, mas não consegue manter um engajamento maior e constante.

O Boticário segmenta bastante seu público-alvo, foca bastante o segmento feminino, mesmo assim possui um alcance significativo, tendo um número de seguidores no período analisado que soma 8.841 .021 no Facebook. Isto é indicador de elevado alcance e aceitação de desafio, e pode ser indicador de um grande engajamento, o que reflete a relação do público-alvo com a marca.

O Boticário utilizou quatro aplicativos para as usuárias postarem dicas e truques de cabelo, makes, unhas e perfumes e também outro aplicativo que permite digitar o nome e homenagear alguém querido no Dia Internacional da Mulher.

No item 4.4, referente ao Concurso cultural, 0 Boticário comunicou três ações promocionais, a saber: a) 24 horas de beleza; b) Concurso para estar no SPFW; e c) Enviar sua foto usando os produtos para concorrer a outros produtos.

No item referente a postagens de campanhas ligadas à responsabilidade social, a empresa 0 Boticário publicou três posts no Facebook com as ideias: a) Compromisso 0 Boticário; b) 35 anos; e c) Fale com 0 Boticário, dois no Linkedin e um no Youtube.

Um resumo da perspectiva da criatividade da estratégia de comunicação institucional nas mídias sociais digitais de 0 Boticário pode revelar que a empresa apresentou originalidade e solução de problemas médias, aceitação de desafios média e flexibilidade alta. A relação entre essas variáveis segue no Gráfico 2.

Gráfico 2 - Estratégia criativo-inovadora de 0 Boticário nas mídias sociais.

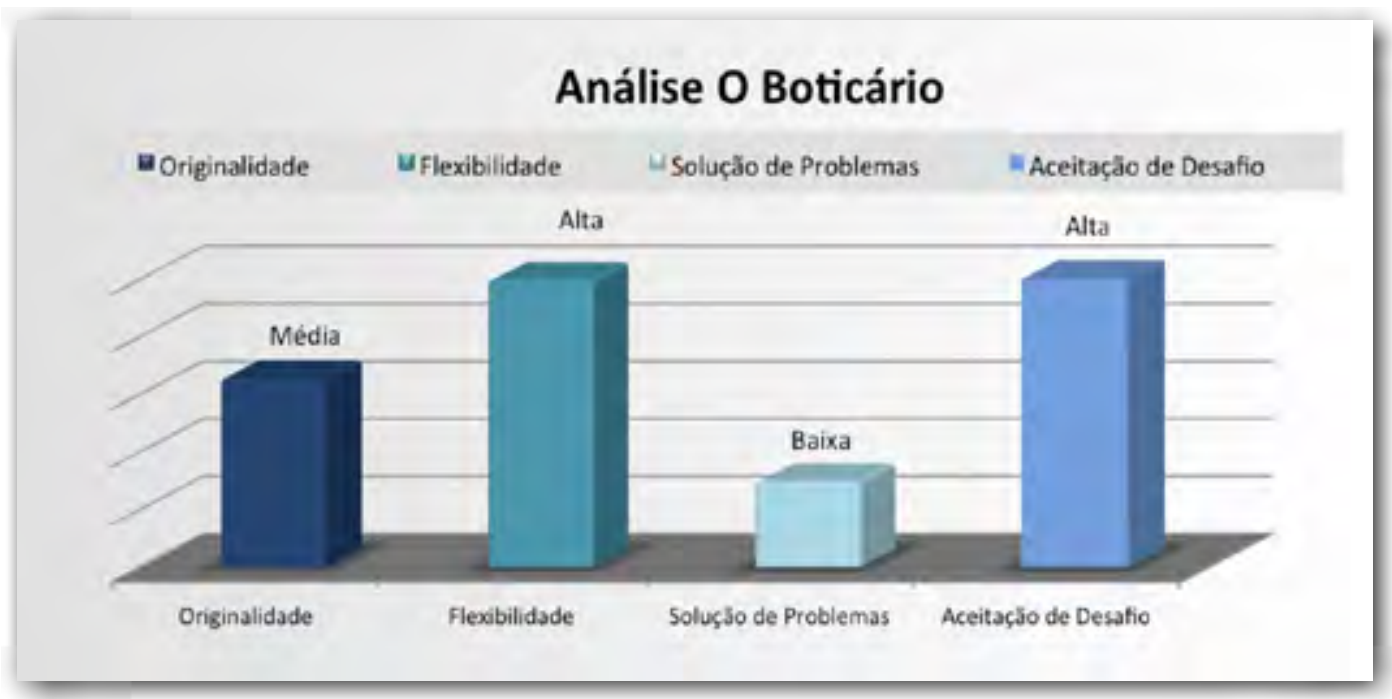

Fonte: Arquivo dos autores. 
De maneira geral, os números coletados no período pesquisado, tornou possível perceber uma ênfase maior na estratégia de 0 Boticário na utilização das redes sociais Twitter e Facebook - nessa ordem de importância - do que nas demais mídias observadas.

O Quadro 3 mostra os principais resultados obtidos pela empresa Cacau Show no que diz respeito às estratégias de comunicação institucional criativa utilizando as mídias sociais digitais.

Quadro 3 - Mídias utilizadas pela Cacau Show: parâmetros e indicadores de criatividade

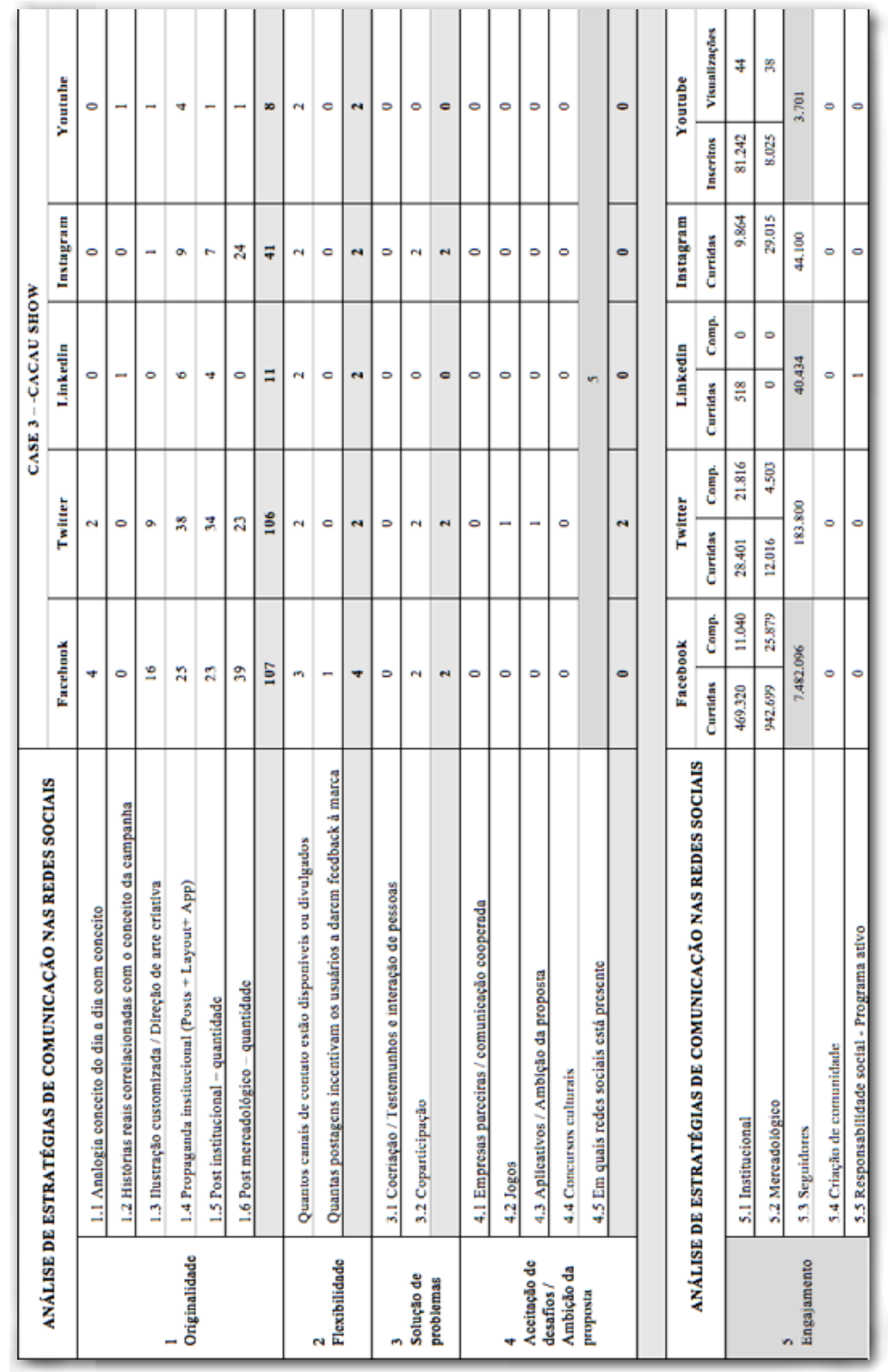

Fonte: Arquivo dos autores.

A empresa Cacau Show foi a que usou menos postagens/novos conteúdos em todas as cinco redes sociais no período analisado e também é a empresa que menos contabilizou comunicação institucional. Sendo assim, pode-se dizer que possui 
a maior ênfase numa estratégia de comunicação mercadológica, pontuando 39 (62,09\%) postagens de venda de produto/ mercadológico versus 23 (37,09\%) postagens institucionais no Facebook. Esta organização tem uma estratégia que pode ser classificada como menos original.

No critério de flexibilidade, a Cacau Show foi a empresa que em termos de tempo de atendimento aos usuários mais postergou as respostas, levando dias para responder, enquanto a exigência da mídia hoje busca respostas em tempo real ou em poucas horas. Mesmo assim, resulta interessante ver como criou em todas as mídias sociais diversos canais que incentivam o cliente ou prospect ao diálogo.

Na variável solução de problemas, vemos que a empresa não fez postagens que estimulassem a cocriação.

Na variável aceitação de desafios, a Cacau Show trouxe dois projetos interessantes em formato de jogo e aplicativo interno. Um deles é o Jogo da memória Cacau Show e o outro, um book para colorir. A empresa aceitou o desafio e produziu jogos para relacionamento e cinestesia com a marca. Uma vez que ambos entendem o uso da web para o smartphone e outros dispositivos móveis, atingem um público infanto-juvenil, mesmo que o aplicativo permita seu uso por todas as idades. Os usuários escolhem cartões interativos de Páscoa e podem digitar a mensagem que desejam enviar para os amigos. 0 ltem 4.3 avalia se as marcas usam o recurso de aplicativos para interação com os usuários. A Cacau Show disponibilizou o aplicativo Entre no clima de Páscoa, com mensagens de carinho para que fossem viralizadas na internet.

O item 5.5 avaliou também o compromisso através de postagens referentes a programas sociais divulgados. A Cacau Show postou uma única ação no Linkedin, a divulgação da oportunidade de se cadastrar e enviar email para a área de recursos humanos, com vistas a uma possível vaga na empresa.

Das empresas analisadas, é a que tem menor número de seguidores e compartilhamentos. Isto pode ser interpretado pelo fato de que o engajamento, aqui representado pelo alcance, assim como a frequência de interações, são menores.

De acordo com o observado, as empresas que investem mais em estratégia de comunicação institucional têm como tendência um maior engajamento com seu público-alvo.

Um resumo sobre a perspectiva da criatividade da estratégia de comunicação institucional nas mídias sociais digitais da Cacau Show traduz que a empresa obteve baixa originalidade, aceitação de desafios e solução de problemas média, assim como flexibilidade média, o que pode ser visto de forma clara no Gráfico 3.

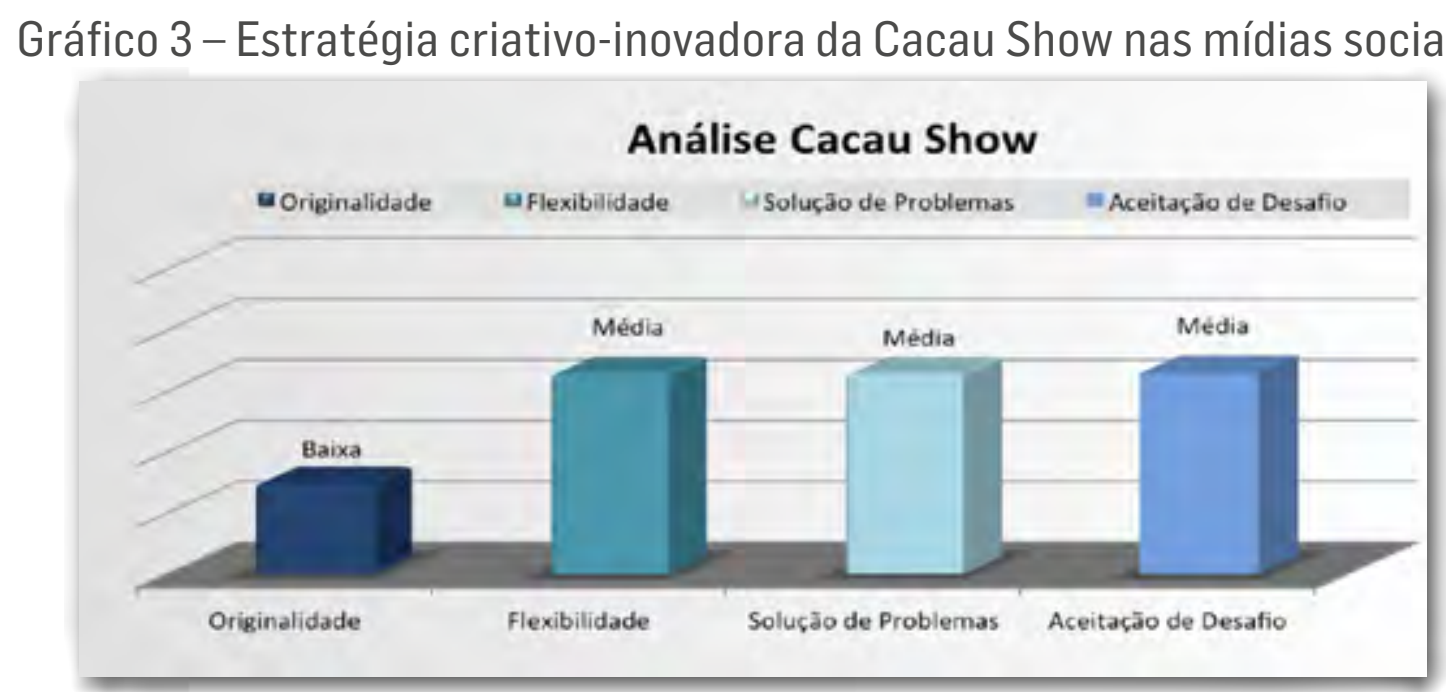

Fonte: Arquivo dos autores. 
De maneira geral, pelos números coletados no período pesquisado, pode-se perceber uma ênfase maior na estratégia da Cacau Show na utilização da rede social Facebook e menos nas demais mídias observadas.

A seguir, os principais resultados observados a partir da análise do comportamento das variáveis verificadas para as três empresas, nas cinco mídias sociais em questão.

Gráfico 4 - Originalidade:

Ênfase na propaganda institucional versus comunicação mercadológica.

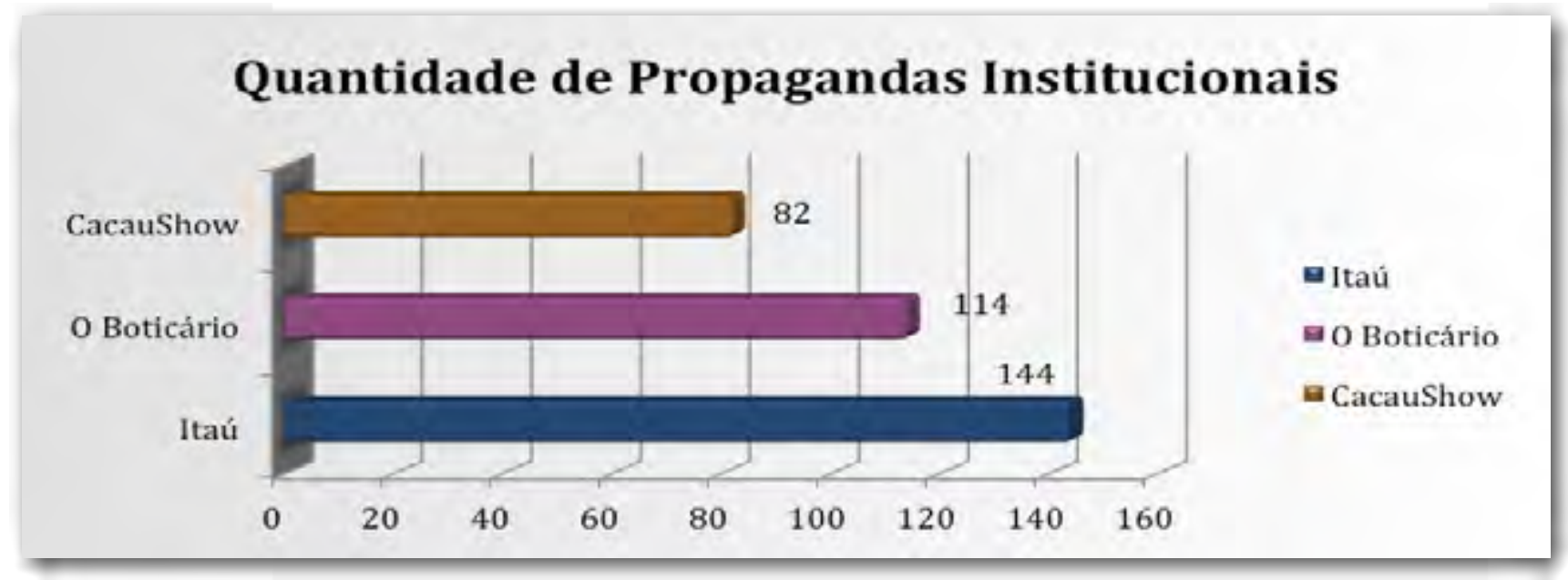

Fonte: Arquivo dos autores.

A originalidade (Gráfico 4), nos limites deste texto, é definida como o indicador de uso criativo e ênfase na propaganda institucional (saindo do tradicional maior uso da comunicação mercadológica por parte das empresas). Após analisar metricamente esse indicador, somamos a quantidade de postagens institucionais, leiautes na interface, promoções de relacionamento e aplicativos de relacionamento. 0 Itaú somou nas cinco redes sociais analisadas a utilização de 144 postagens/exibições institucionais, enquanto 0 Boticário, 114 postagens e a Cacau Show, 82 postagens. Tal aspecto reflete o engajamento que é o resultado do relacionamento com os públicos impactados. 0 Itaú aparece em primeiro lugar, com 2.450.112 curtidas acima das demais organizações analisadas, que pontuaram 589.345 e 171.040 respectivamente. Dessa forma, este estudo conclui que o Itaú obteve a maior pontuação na variável originalidade de sua estratégia de comunicação.

0 Gráfico 5 aborda o comportamento da flexibilidade da estratégia de comunicação das três empresas estudadas.

Gráfico 5 - Flexibilidade:

Quantidade de canais de comunicação disponibilizados para o público-alvo.

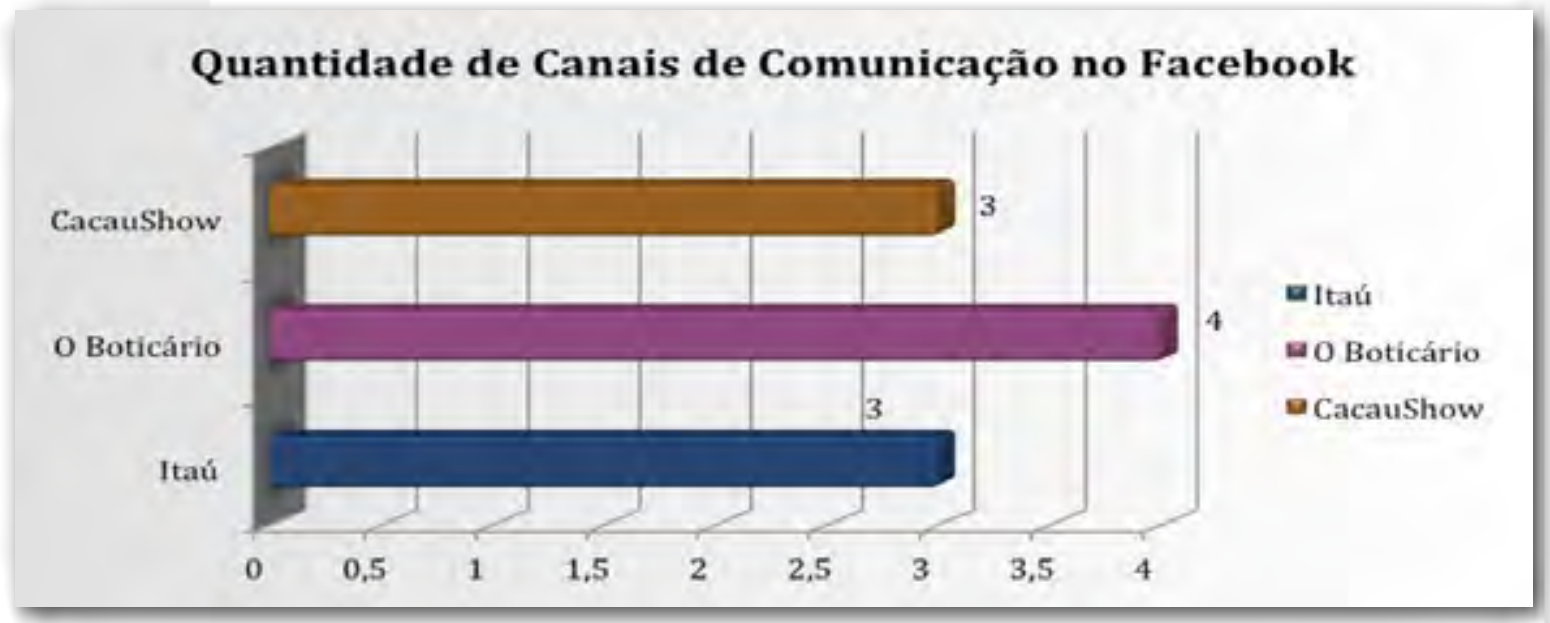

Fonte: Arquivo dos autores. 
Para estudar a flexibilidade, analisou-se como a marca explicitou seu interesse em escutar o usuário nas mídias sociais digitais. Dessa forma, foram observados quantos canais estavam disponíveis ou sendo divulgados para o usuário dar feedback, reclamar, elogiar ou simplesmente conversar com a marca, oferecendo seus critérios.

O Boticário foi a marca que mais explicitou interesse em escutar o usuário, em uma única rede. No Facebook, a empresa utilizou quatro canais de comunicação (espaço no menu "sobre" institucional, espaço no feed comentários, dúvidas por inbox e aplicativo criado "Fale com 0 Boticário"), enquanto Itaú e Cacau Show utilizaram só três canais de comunicação, que já são padrão para contato entre a empresa e o usuário nas mídias sociais digitais. Mesmo assim, quando é analisado o conjunto de todas as redes sociais, percebe-se que, somando todos os canais de comunicação com o cliente nas mídias sociais digitais, o Itaú supera 0 Boticário, como é mostrado no Gráfico 6.

Gráfico 6 - Solução de problemas: cocriação.

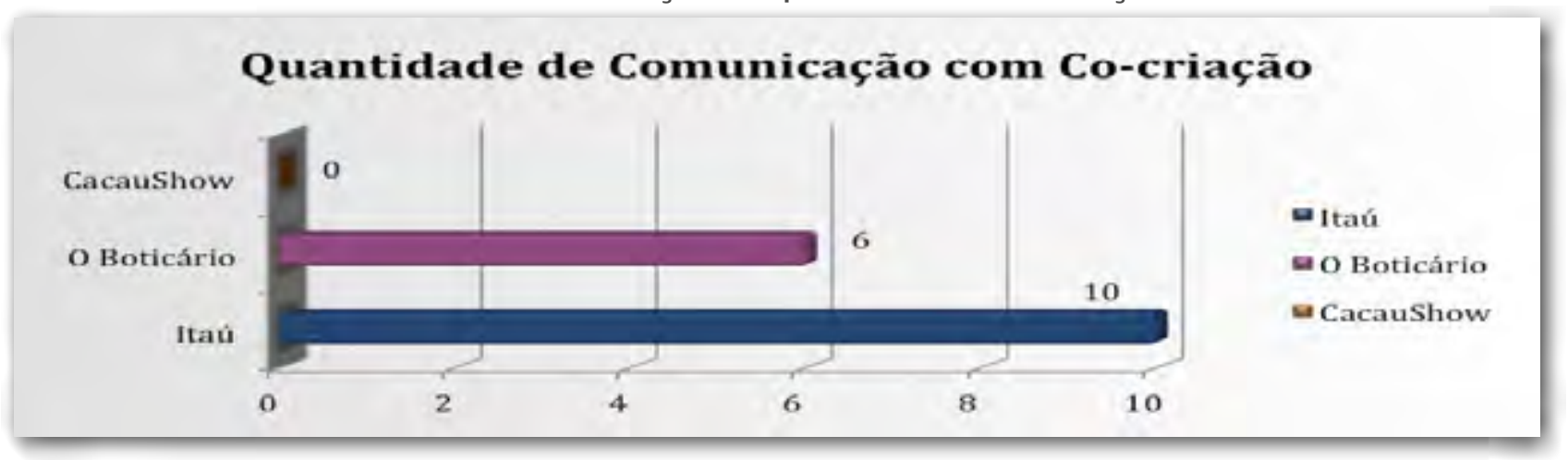

Fonte: Arquivo dos autores.

Para avaliar a capacidade de solução de problemas das estratégias de comunicação das empresas estudadas nas redes sociais digitais, vários indicadores foram requeridos, mas o indicador que mais se destacou foi o de cocriação, entendido aqui como o incentivo oferecido pela empresa para a interação das pessoas em função de construir promoções, postagens, produtos e serviços de maneira conjunta com a organização.

Como pode ser observado no Gráfico 6, o Itaú foi a organização que melhor trabalhou com esse critério, apresentando dez postagens no período total de campanha analisado, enquanto 0 Boticário usou seis postagens e a Cacau Show não pontuou nesse recurso de comunicação, entendido como solução criativa de problemas.

Vejamos a seguir, no Gráfico 7, outro item para avaliar a criatividade das estratégias de comunicação digital das empresas estudadas.

Gráfico 7 - Aceitação de desafios/Ambição de proposta: empresas parceiras/comunicação cooperada.

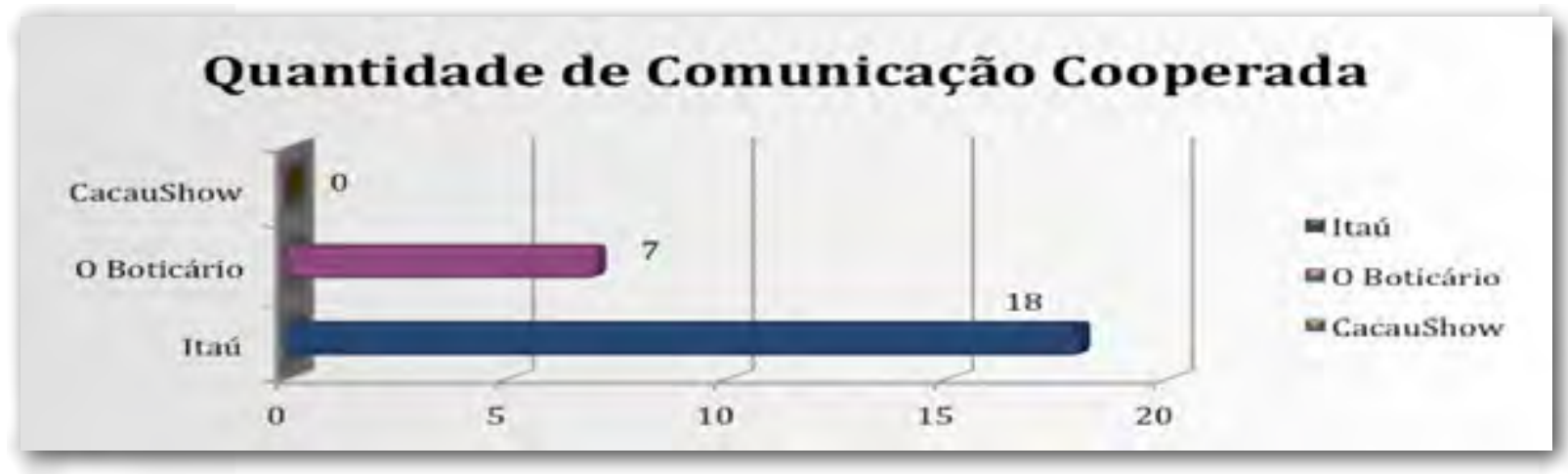

Fonte: Arquivo dos autores. 
No critério de aceitação de desafios/ambição da proposta, é ressaltado o indicador empresas parceiras/comunicação cooperada dentro das redes sociais, que mostra a intenção da organização em construir um relacionamento sólido com os clientes e prospects, estando sempre presente para seus usuários, mas pensando num atendimento mais completo, utilizando outros parceiros para oferecer sempre mais vantagens para o público-alvo. 0 Itaú ocupou neste quesito o primeiro lugar, somando o total de dezoito postagens relacionadas a empresas parceiras, enquanto O Boticário somou seis e a Cacau Show não realizou nenhuma ação ou postagem cooperada.

Por último, analisou-se o engajamento, a partir do Gráfico 8.

Gráfico 8 - Engajamento indicador de posts curtidos e compartilhados com estratégia comercial e institucional.

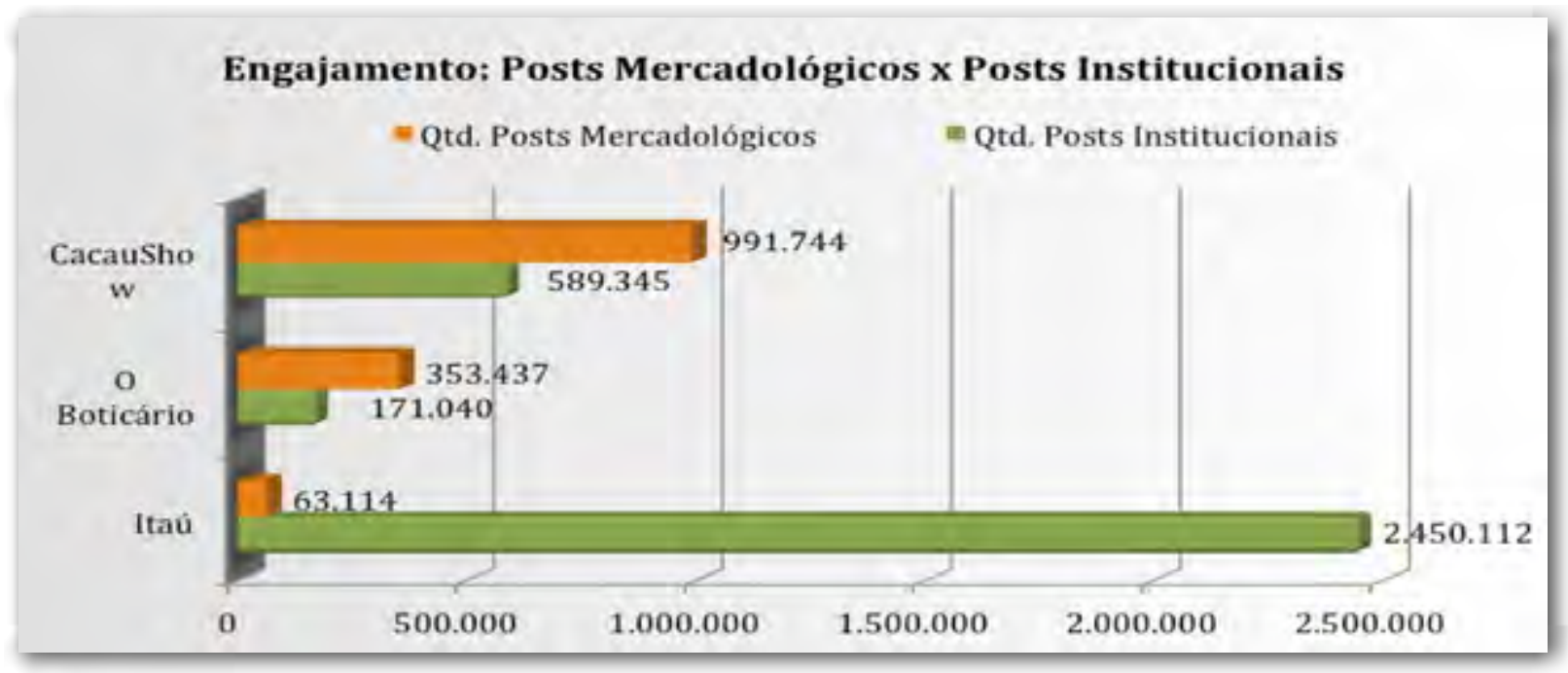

Fonte: Arquivo dos autores.

O engajamento foi a última variável estudada, tendo-se analisado o indicador de posts curtidos e compartilhados, tanto os realizados com foco na estratégia comercial como na institucional, em todas as redes sociais. De acordo com o observado no Gráfico 5, o Itaú lidera novamente, com maior engajamento do usuário, pontuando em postscurtidos institucionalmente, com 2.450.112, e também mercadologicamente, com 1.298.221; O Boticário já apresenta o maior equilíbrio em curtidas institucionais versus mercadológicas, 171.040 e 353.437, respectivamente; e a Cacau Show, com um uso muito maior de uma estratégia de comunicação com foco mercadológico, somou 589.345 posts institucionais curtidos contra 991.744 mercadológicos.

\section{CONSIDERAÇÕES FINAIS}

Todas as marcas analisadas possuem números de seguidores próximos, apresentam um alcance de usuários com certa paridade. Mas, de acordo com o observado nesta pesquisa, após o usuário decidir seguir a empresa, o que sustentará 0 relacionamento - e mais ainda o engajamento, gerando retorno através das redes sociais - é o conceito de comunicação integrada adotado. Se este aplica maior ênfase na comunicação institucional e, dentro desta, na propaganda institucional versus a ênfase tradicional na comunicação mercadológica, o engajamento tende a ser maior. 0 engajamento pode ser visto como uma variável motivacional-afetiva, que descreve o compromisso do cliente com a marca, assim como o grau de intimidade do cliente com a mesma e seu nível de influência (Haven, Bernoff; Glass, 2007, apud Saccaro, 2015).

Cada empresa montou um mix de mídias digitais que considerou mais atraente para o seu produto e sua imagem. Assim, o Itaú deu prioridade ao Facebook junto com o Twitter, nessa ordem de importância, enquanto 0 Boticário priorizou 0 
Twitter e em segundo lugar o Facebook para sua comunicação. Por outro lado, a Cacau Show apostou mais no Facebook e nem tanto nas outras redes sociais digitais.

Esta pesquisa comprovou que as redes sociais digitais podem ser utilizadas não apenas como instrumentos de comunicação mercadológica e suporte da estratégia comercial, senão também como instrumentos da comunicação institucional, redundando em estratégias de relacionamento.

Os novos públicos apresentam novos comportamentos de consumidor, sendo exemplo disso o interesse pelos games, que deve ser uma ferramenta de fidelização que se utilize ainda mais no futuro como parte da comunicação institucional das organizações.

A flexibilidade foi analisada através de vários indicadores, mas fundamentalmente através do número de canais de comunicação disponibilizados pela empresa nas mídias digitais para ouvir o cliente ou prospect. A solução de problemas envolveu principalmente 0 item incitação por parte da empresa à cocriação dos participantes em seus projetos. A aceitação de desafio foi analisada através de vários indicadores, mas o principal foi o número de parceiros envolvidos nas campanhas e o investimento em comunicação cooperada com essas empresas parceiras, divulgando os serviços oferecidos em conjunto. Em todos esses itens, a empresa Itaú se destacou, sendo seguida pelo O Boticário e, em terceiro lugar, pela Cacau Show.

Esta análise salienta que a estratégia de comunicação integrada do Itaú priorizou a comunicação institucional, enquanto O Boticário utilizou um mix de comunicação no qual predominou a comunicação mercadológica, mas com pouca diferença da institucional. Já a Cacau Show empregou um composto de comunicação, no qual a predominância da comunicação mercadológica sobre a institucional foi ainda mais evidente.

Foi possível inferir que todas as estratégias empregadas pelas três empresas - utilizando diferentes graus de criatividade, de acordo com as variáveis e indicadores observados - permitiram obter resultados elevados e inovadores em termos de engajamento dos clientes e prospects. Percebeu-se também que as estratégias de comunicação institucional utilizando as mídias sociais empregaram diferentes mixes das variáveis de criatividade estudadas. Assim, é possível afirmar que a empresa que investe mesmo em originalidade é o Banco Itaú.

Este trabalho permitiu uma primeira aproximação a um assunto polêmico, como são as estratégias de comunicação institucional consideradas criativas e inovadoras das empresas nas mídias sociais digitais. Como salientado desde 0 início, as estratégias possuem diversos níveis de realização e planejamento. Tentou-se diagnosticar aqui, seguindo um sistema de variáveis e indicadores qualiquantitativos elaborado pelos autores, as que são mais criativas e que podem levar a resultados inovadores em termos de engajamento, reputação da marca e vendas. Na presente pesquisa, não foram considerados os resultados em imagem, reputação e vendas, o que pode ser objeto de estudos posteriores.

Este estudo possibilitou elaborar claros indicadores de criatividade que permitiram visualizar de forma clara a criatividade e inovação nas estratégias de comunicação institucional utilizadas pelas empresas estudadas nas mídias sociais.

Como sugestão, se indica também utilizar métodos de criatividade mais tradicionais, como o brainstorminge o sinéctico, entre outros considerados mais recentes, como design thinking e storytelling no processo de elaboração dessas estratégias e na procura de um diferencial para as mesmas. 
A comunicação planejada com estratégias criativas que integrem de maneira orgânica suas quatro modalidades (institucional, mercadológica, interna e administrativa) no mundo digital é o caminho para um planejamento completo e de sucesso para as empresas.

As estratégias criativas de cada empresa devem ter também uma adequação ao produto, ramo de atuação e tipo de público específico, mas isso deve ser objeto de ulteriores pesquisas.

\section{REFERÊNCIAS}

CAPUTO, Victor. Brasil é o país no qual internautas passam mais tempo online. Exame.com, 04/12/1014. Disponível em: $<$ http://exame.abril.com.br/tecnologia/ noticias/brasil-e-0-pais-no-qual-internautas-passam-mais-tempo-online>. Acesso em: 03 mar. 2015.

CHAGAS, Paulo. Internauta passa quase quatro horas por dia na web. EBC Agência Brasil. Disponível em: <http://agenciabrasil. ebc.com.br/pesquisa-e-inovacao/noticia/2014-03/internauta-passa-quase-quatro-horas-por-dia-na-web>. Acesso em: mar. 2015.

CHIBÁS ORTIZ, Felipe. Creatividad, comunicación y cultura: gestión innovadora de proyectos educativos-culturales en la era digital. La Habana, Cuba: Pueblo y Educación, 2015.

. Métodos de criatividade para a gestão de projetos inovadores. R/T - Revista de Informação e Tecnologia, v. 4, n. 1, 2014.

Ciclo do marketing digital: tática e estratégia blended. Revista Eniac Pesquisa, Guarulhos (SP), v. 2, n.1, p. 62-74, jan.- jul. 2013.

CHIBÁS ORTIZ, Felipe; PANTALEON, Efrain; ROCHA, Tatiana. Gestão da inovação e da criatividade hoje: apontes e reflexões. Holos, on-line, n. 3, p. 15-26, 2013.

CORRÊA, Elizabeth Saad. Estratégias para a mídia digital. São Paulo: Senac, 2003.

DI FELICE, Massimo. Auréola digital: a crise dos pontos de vista centrais e o fim do direito exclusivo da edição das informações. In: OLIVEIRA, Ivone de Lourdes; MARCHIORI, Marlene (Org.). Redes sociais, comunicação e organizações. São Caetano do Sul, SP: Difusão, 2012.

DONNELLY, Dermot F.; BONIFACE, Suzanne. Consuming and creating: early-adopting science teachers' perceptions and use of a wiki to support professional development. Computers \& Education, n. 68, p. 9-20, 2013.

ÉPOCA NEGÓCIOS; A.T. KEARNEY. Ranking Prêmio Best Innovator: as empresas mais inovadoras do Brasil. Época Negócios, 2014. Disponível em: <http://epocanegocios.globo.com/inspiracao/carreira/noticia/2014/05/lorrana-scarpioni-brasileira-queganha-dinheiro-com-tempo-livre.html>. Acesso em: 21 fev. 2015.

EXAME. As 50 empresas mais inovadoras do Brasil. 0 Boticário lidera. Disponível em: <http://exame.abril.com.br/negocios/ noticias/as-50-empresas-mais-inovadoras-do-brasil-boticario-lidera, 25/08/2014>. Acesso em: 15 mar. 2015.

FAST COMPANY. Ranking das 50 empresas mais inovadoras do mundo. Disponível em: < http://www.digitaleverywhere.com.br/ blog/2014/02/>. Acesso em: 20 maio 2014. 
GABRIEL, Martha. Marketing na era digital: conceitos, plataformas e estratégias. São Paulo: Novatec, 2010.

HAVEN, Brian; BERNOFF, Josh; GLASS, Sarah. Marketing's new key metric: engagement. Marketers must measure involvement, interaction, intimacy and influence. Forrester Research, August 8, 2007.

JENKINS, Henry. Cultura da convergência. São Paulo: Aleph, 2009.

KUNSCH, Margarida, M. Krohling. Planejamento de relações públicas na comunicação integrada. 4. ed. - rev., atual. e ampl. São Paulo: Summus, 2003.

OKADA, Alexandra. Colearn 2.0: Refletindo sobre o conceito de co-aprendizagem via REAs na web 2.0. In: BARROS, Daniela et al. (Org.). Educação e tecnologias. reflexão, inovação e prática. Lisboa: Universidade Aberta, 2011. p. 119-139.

OLHAR DIGITAL. Veja a lista das redes sociais mais acessadas no Brasil - 2014. Disponível em: <http://olhardigital.uol.com.br/ noticia/42266/42266?utm_source=facebook\&utm_medium=site\&utm_campaign=lista\%20redes\%20sociais $\% 20$ mais $\% 20$ acessadas>. 28/05/2014. Acesso em: 07 jul. 2014.

ROSA, Mario. A reputação na velocidade do pensamento. São Paulo: Geração Editorial, 2006.

SACCARO. 0 que é (de fato) engajamento nas mídias sociais? Disponível em: <http://www.scup.com/pt/blog/o-que-e-de-fatoengajamento-nas-midias-sociais>. Acesso em: 18 mar. 2015.

TERRA, Carolina Frazon. Mídias sociais...e agora? São Caetano do Sul, SP: Difusão; Rio de Janeiro: Senac, 2011.

TORRE, Saturnino de la. Creatividad cuántica: una mirada transdisciplinar. Encuentros Multidisciplinares, v. X, n. 28, p. 5-21, jan.-abr. 2008.

TURCHI, Sandra. Estratégias de marketing digital e e-commerce. São Paulo: Atlas, 2012.

YIN, Robert K. Case study research: design and methods. California: Sage, 2009.

Artigo recebido em 22.04.2015 e aprovado em 14.06.2015. 